\title{
Technical Note: The Definition of New Dental Morphological Variants Related to Malocclusion
}

\author{
Marin A. Pilloud ${ }^{1, *}$ \\ ${ }^{1}$ Department of Anthropology, University of Nevada, Reno, NV 89557
}

Keywords: dental crowding, midline diastema, canine diastema, overbite, underbite, overjet

ABSTRACT Since the codification of the Arizona State University Dental Anthropology System over 25 years ago, few additional morphological traits have been defined. This work serves to expand the current suite of traits currently collected by biological anthropologists. These traits surround various issues of malocclusion and follow clinical definitions of these traits as well as incorporate observed population variation in character states. These traits include issues of spacing (i.e., diastema and crowding) as well as mandibular and maxillary occlusion (i.e., overbite, underbite). A discussion of the etiology and utility of these traits in bioarchaeological and forensic anthropological research is also given.

The Arizona State University Dental Anthropology System (ASUDAS) has been the standard in defining morphological variants of the teeth for over 25 years (Turner et al., 1991). This publication outlines 36 traits of the dentition as well as rocker jaw, and mandibular and palatine tori. This original work is based on a rich literature defining morphological variation of the teeth (e.g., Dahlberg ,1956; Hanihara ,1961; Harris and Bailit, 1980; Hrdlička ,1921; Morris, 1970; Morris et al., 1978; Scott, 1977; Scott, 1980; Tomes, 1914; Turner ,1970; Turner, 1971). However, since its publication, there have only been a handful of additional traits defined, including the canine mesial ridge (Irish and Morris, 1996), maxillary premolar accessory ridges

(Burnett et al., 2010), deciduous morphological variants (Sciulli, 1998), and molar crenulations (Pilloud et al., 2017).

There is room to expand our current understanding of dental morphological variation and to create definitions of additional traits. This paper broadens the current suite of traits and defines variants that may be of interest in bioarchaeological and forensic studies of dental variation that surround issues of malocclusion: canine/midline diastema, dental crowding, and maxillary and mandibular overjet. While these variants are not new to those working with teeth or the human skeleton (e.g., Alt and Türp, 1998; Lasker, 1950), a working definition and scoring system has not yet been created within dental anthropology, with the exception of the midline diastema. Each trait is discussed below and a definition and scoring system is provided.

\section{Diastema}

While the midline diastema has been defined in the new volumes by Scott and Irish (2017) and Edgar (2017), their definitions differ as to what exactly constitutes a diastema, they do not offer grades of expression, nor do they incorporate a canine diastema. The definition presented here is based on the definitions provided in these two works as well as several other preceding studies. Further, the incorporation of a canine diastema is included. Therefore, diastemata can occur in the maxillary midline or on either side of the mandibular or maxillary canine. The proposed scoring system incorporates both types of diastemata; however, they are discussed separately below.

\section{Midline maxillary diastema}

Midline maxillary diastemata have been reported on extensively in the clinical literature (e.g., Chu et al., 2011; Kamath and Arun, 2016; Shashua and Årtun, 1999). Anthropological research on midline maxillary diastemata has identified population, sex, and age differences in the occurrence of this trait (Edgar, 2007; Horowitz, 1970; Lavelle, 1970; McVay and Latta, 1984; Nainar and Gnanasundaram, 1989; Richardson et al., 1973). This discussion focuses on the adult dentition, as midline diastemata can commonly be found in primary and mixed dentition, and can be lost as the

\section{*Correspondence to:}

Dr. Marin A Pilloud, Department of Anthropology, University of Nevada, Reno mpilloud@unr.edu 
permanent teeth erupt (Gkantidis et al., 2008).

There are many definitions of diastemata that incorporate various space sizes and grades of expression. In a joint publication by the World Health Organization (WHO) and the International Dental Federation (IDF), a midline diastemata is defined as a space of more than 2.0 $\mathrm{mm}$ (Bezroukov et al., 1979). In their new volume on dental morphology, Scott and Irish (2017) define the midline maxillary diastema as any space greater than $0.5 \mathrm{~mm}$ (following Lavelle, 1970), and see no need to further define the trait beyond present or absent (based on Irish, 1993). Edgar (2017) also defines midline diastema; however, in her scoring system, $1.0 \mathrm{~mm}$ of space is required for presence.

None of the current scoring systems allow for different grades of expression and only focus on presence/absence. However, in their study of nearly 6,000 radiographs, McVay and Latta (1984) found a statistically significant difference in midline diastema size between their sample groups of White, Black, and "Oriental" (sizes defined as $<0.49,0.5-1.49,>1.5 \mathrm{~mm}$ ). A study of 759 American Black and White children also found there to be size differences, with $19 \%$ of Blacks and $10 \%$ of Whites having a midline diastema over $2 \mathrm{~mm}$ (Horowitz, 1970). Differences in size of midline diastemata were also reported among a sample in South India (Nainar and Gnanasundaram, 1989). It may therefore be useful to separate out grades of expression in global studies of diastema.

\section{Canine diastema}

Canine diastemata can occur in the maxilla (sometimes referred to as premaxillary diastema) between the maxillary canine and the lateral incisor (Schultz, 1948), or between the canine and third premolar (Mongtagu, 1989). Canine diastemata also occur on the mandibular canine, again on either side of the tooth. Lavelle's (1970) study of diastemata among 656 individuals found the majority of diastemata were between the maxillary third premolar and canine and the maxillary second incisor and canine. A study by Keene (1963) evaluating midline and canine diastemata $(>0.5 \mathrm{~mm})$ among 183 white males found the most common diastema location was between the maxillary canine and the third premolar (even more common than midline diastema). Keene also found that the majority of diastemata were between 1 and $3 \mathrm{~mm}$ in size. These studies highlight the potential role of canine diastemata in defining human population variation.

\section{Definition and Scoring System: Diastema}

In this proposed system, a diastema is defined as any gap between the teeth with a separation of $0.5 \mathrm{~mm}$ or more. Diastemata can be scored in three locations: 1) maxillary central incisors, 2) maxillary canines, and 3) mandibular canines (Figure 1). Among the canines, the separation can occur on either side, between the canine and the lateral incisor, or the canine and the third premolar. The current scoring system does not differentiate between the two locations.

$$
\begin{aligned}
& 0 \text { - absent }(<0.50 \mathrm{~mm}) \\
& 1 \text { - low-grade diastema } 0.5-1.49 \mathrm{~mm} \\
& 2 \text { - high-grade diastema } \geq 1.5 \mathrm{~mm}
\end{aligned}
$$

Affected teeth: maxillary central incisors, mandibular canine, maxillary canine

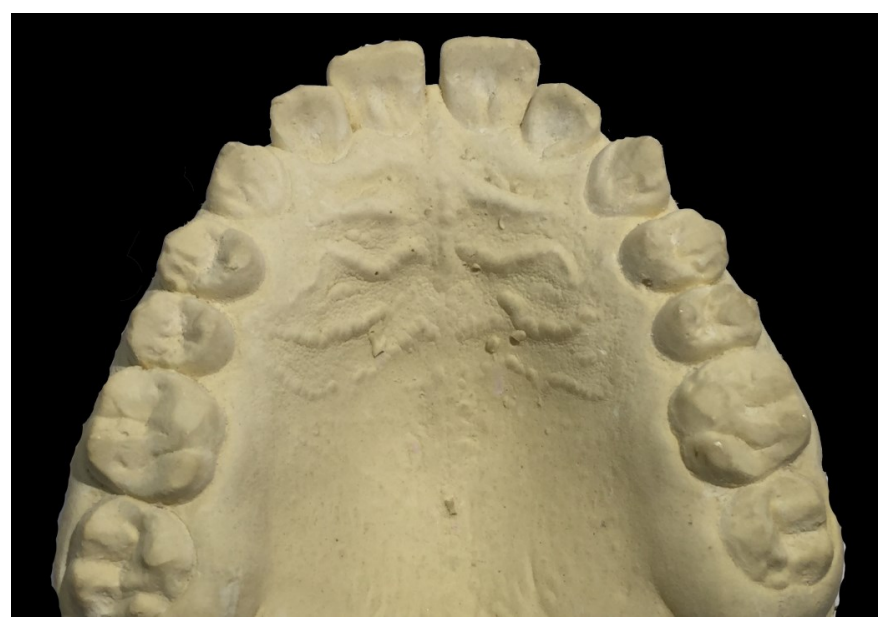

Figure 1. Individual with a midline maxillary diastema (score of 1 ), and a canine diastema (score of 1 ) (photo courtesy of G. Richard Scott).

\section{Dental Crowding and Occlusion}

In this discussion, it is important to define occlusion and note the ideal model of occlusion to identify deviations from normal (i.e., malocclusions). Occlusion "relates to the arrangement of maxillary and mandibular teeth and to the way in which teeth contact" (Türp et al., 2008:446). An ideal form of occlusion occurs when the "skeletal bases of maxilla and mandible are of the correct size relative to each other and the teeth [are] in correct relationship in all three planes of space at rest" (Hassan and Rahimah, 2007:3). The three planes being anteroposterior, vertical, and transverse. Therefore, malocclusion would be any deviation from this norm to include malpositioning of teeth within the dental arcade (i.e., displacement or rotation.), or a disassociation between the dental arches in any of the three planes of direction (Proffit, 1986).

While there are many references regarding the treatment of malocclusion in the clinical literature (Angle, 1907; Dahiya et al., 2017; Singhal et al., 2015), there is little consensus on how it is quantified or fully defined (Tang and Wei., 1993). The earliest and still commonly used classification of malocclusion is that offered by Angle (1899). In this work, three types of malocclusion are described, all in relation to the position of the upper and lower first molar. Class I describes normal positions of the molars, and can be further subdivided into Class I normal and Class I - malocclusion. Class I - malocclusion 
includes crowding, spacing, and rotations of the anterior teeth, even though the molars may be in normal alignment (Silva and Kang, 2001). Class II is a retrusion of the jaw (i.e., overbite) in which the mandibular teeth occlude posterior to normal (i.e., lower first molar occludes posterior to the upper first molar). Class III is a protrusion of the lower jaw (i.e., underbite) in which the mandibular teeth occlude mesial to normal, typically by the length of one premolar, but may be a larger distance in severe cases.

Since 1899, various other methods have been proposed to quantify malocclusion (e.g., Baume and Maréchaux, 1974; Björk et al., 1964; Little, 1975). In the late 1960's, research out of the University of Toronto developed the Orthodontic Treatment Priority Index to quantify various types of malocclusion (Grainger, 1967). In the late 1970's, the World Health Organization (WHO) and the International Dental Federation (Fédération Dentaire Internationale- FDI, now called the World Dental Federation) devised a simple method to record malocclusion. This system includes crowding and diastemata as "space conditions". In this system, crowding is defined as present when $>2 \mathrm{~mm}$ of space deficiency is observed between the size of the dental arch and the anterior teeth (i.e., incisors, canine, and both premolars). Deviations from normal occlusion in this system include maxillary and mandibular overjets, openbites, and midline shifts, among others (Bezroukov et al., 1979).

As malocclusion can include crowding and malposition of the jaws, the following definitions of malocclusion are offered, generally following the definitions of Angle (1899) and those of the WHO/FDI (Bezroukov et al., 1979).

\section{Definition and Scoring System: Dental Crowding}

Dental crowding (Angle's Type I - malocclusion) is defined as the presence of any tooth that deviates from ideal alignment through either rotation or displacement. The system proposed here is based on that described by Van Kirk and Pennell (1959). Rotation and displacement can be categorized into two types: major or minor. Minor rotation is under $45^{\circ}$, where major rotation is defined as $45^{\circ}$ or greater from ideal alignment. Minor displacement is under $1.5 \mathrm{~mm}$, and major displacement is $1.5 \mathrm{~mm}$ or greater from ideal alignment either labially or lingually (Figure 2). In the original system outlined in Van Kirk and Pennell (1959), each tooth is scored and scores are summed to assess the level of malocclusion. This system could be cum-

Ideal Alignment

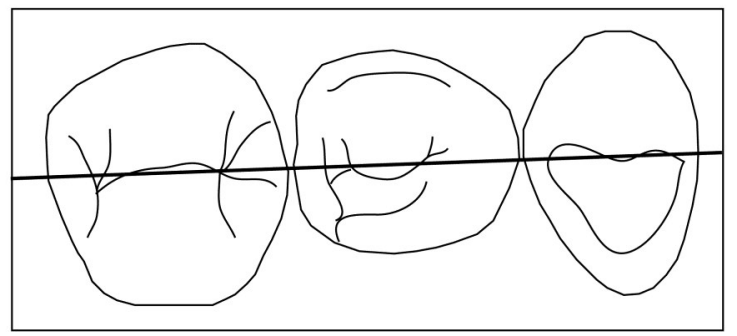

Minor Rotation

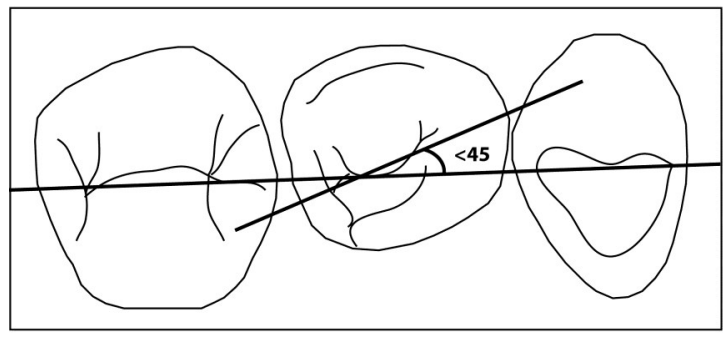

Minor Displacement

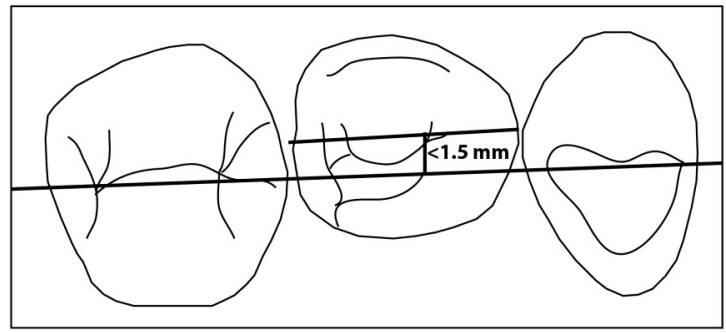

Major Rotation

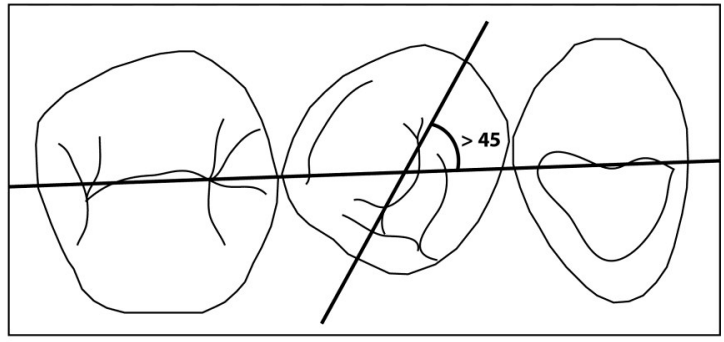

Major Displacement

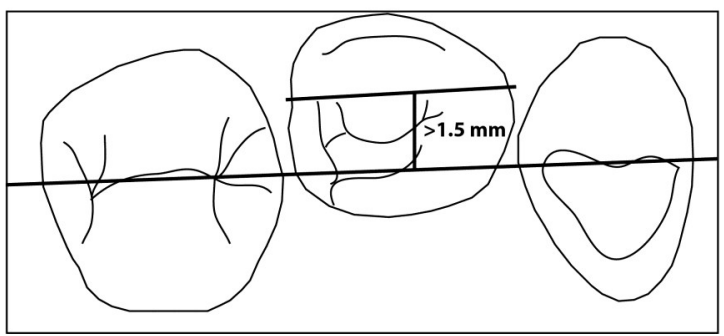

Figure 2. Scoring of rotation and displacement as part of dental crowding for lateral teeth. Based on Van Kirk and Pennell (1959). 
bersome in the work of the biological anthropologist and could be impossible when faced with teeth that may be missing ante- or post-mortem. Therefore, the system below is proposed for use in forensic anthropological or bioarchaeological settings.

Crowding is subdivided into incisal and (first and second incisors) and lateral (canine and premolars). The molars are not considered in this system. If all teeth in each class are not present, the level of crowding cannot be scored; allowing for some, but not a lot of missing teeth. If bilateral winging is observed and no other crowding is present in the incisal region, crowding should not be scored (i.e., leave the entry blank for crowding and score winging in its place to avoid redundant data).

\section{Incisal (first and second incisor)}

0 - absent - both teeth are in ideal alignment (no rotation and no displacement)

1 - slight - one or both teeth show slight deviations from ideal alignment (rotation between $1^{\circ}$ and $44^{\circ}$ and/or displacement between 0.1 and $1.4 \mathrm{~mm}$ )

2 - moderate - at least one tooth shows major malalignment (rotation $\geq 45^{\circ}$ and/or displacement $\geq 1.5 \mathrm{~mm}$ ), the other may be in ideal alignment or show slight deviation

3 - severe - both teeth show major malalignment (rotation $\geq 45^{\circ}$ and/ or displacement $\geq 1.5 \mathrm{~mm}$ )

Affected areas: mandibular and maxillary incisors

\section{Lateral (canine and third and fourth premolar)}

0 - absent - all three teeth are in ideal alignment (no rotation and no displacement)

1 - slight - one or all three teeth show slight deviations from ideal alignment (rotation between $1^{\circ}$ and $44^{\circ}$ and/or displacement between 0.1 and 1.4 $\mathrm{mm}$ )

2 - moderate - at least one tooth shows major malalignment (rotation $\geq 45^{\circ}$ and/or displacement $\geq 1.5 \mathrm{~mm}$ ), the others may be in ideal alignment or show slight deviation

3 - severe - all three teeth show major malalignment (rotation $\geq 45^{\circ}$ and/or displacement $\geq 1.5 \mathrm{~mm}$ )

Affected areas: mandibular and maxillary canines and premolars

To illustrate this scoring method, two worked examples are presented. In Figure 3, there is a set of mandibular teeth that illustrate crowding and can be scored as follows:

Incisal Right and Left - 0 - there is no rotation or displacement of teeth on the right or left sides

Lateral Left - 2 - the fourth premolar shows slight rotation $\left(<45^{\circ}\right)$ but shows major displacement $(\geq$ $1.5 \mathrm{~mm})$
Lateral Right - 2 - the right canine shows minor rotation $\left(<45^{\circ}\right)$ and the third premolar shows major displacement $(\geq 1.5 \mathrm{~mm})$

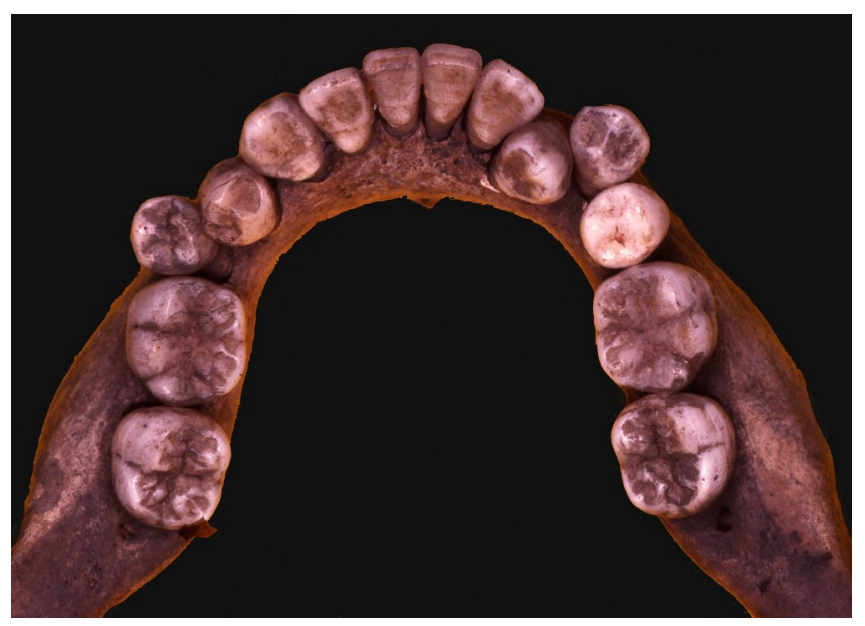

Figure 3. Mandibular teeth that illustrate crowding (photo courtesy of G. Richard Scott and Christy G. Turner, II).

Figure 4 illustrates a set of maxillary teeth with crowding that can be scored as follows:

Incisal Right - 2 - the right second incisor shows major displacement $(\geq 1.5 \mathrm{~mm}$ ) and the central incisor shows minor rotation $\left(<45^{\circ}\right)$

Incisal Left - 2 - the left second incisor shows major displacement $(\geq 1.5 \mathrm{~mm})$ and the central incisor shows minor rotation $\left(<45^{\circ}\right)$

Lateral Left and Right - 0 - there is no rotation or displacement of teeth on either side

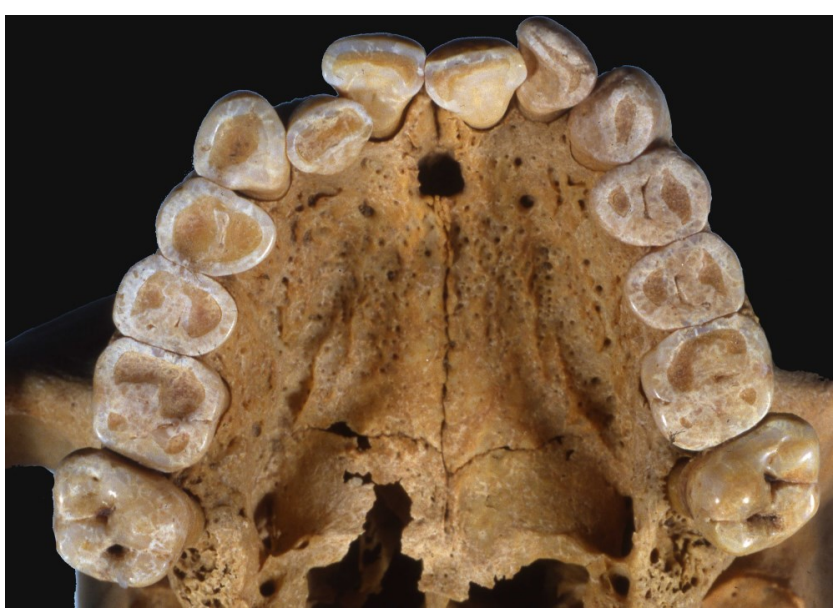

Figure 4. Maxillary teeth that illustrate crowding (photo courtesy of G. Richard Scott and Christy G. Turner, II). 


\section{Discussion}

Diastema

There may be a number of causes for a midline diastema, to include a large superior labial frenum, supernumerary teeth, missing teeth, peg teeth, digit sucking, abnormal arch size, muscular imbalances in the oral region (Huang and Creath, 1995), ossifying fibroma of the palate (Kamath and Arun, 2016), or even a tongue piercing (Tabbaa et al., 2010). However, genetics may also play a role. A familial study on the maxillary midline diastema reported the heritability to be $0.32 \pm 0.14$ among a white sample and $0.04 \pm 0.16$ in a black sample. The researchers concluded that among the white sample there was a stronger genetic basis for midline diastema and that the environment could be playing a larger role in trait expression among the black sample (Gass et al., 2003). While this study reports low heritabilities, many studies have documented population differences in the expression of the trait (Huang and Creath, 1995; Lavelle, 1970; McVay and Latta, 1984; Scott and Irish, 2017), which suggests the utility of the trait in bioarchaeology and forensic anthropology. Further, as several studies have illustrated prevalence rates of canine diastemata in different populations (e.g., Keene, 1963), this trait may have value in biological anthropological studies as well.

\section{Malocclusion}

Dental crowding and malocclusion are often discussed in relation to the adoption of agriculture and the introduction of soft foods as part of the masticatory-functional hypothesis (Carlson and Van Gerven, 1977; Corruccini, 1984; Corruccini et al., 1983; Larsen, 2015). In this discussion, malocclusion encompasses two distinct features: malalignment of the teeth (i.e., crowding) and malalignment of the jaws (i.e., overbite and underbite). While these are related conditions of occlusion, they may have separate etiologies. While over- and under-bites have not been traditionally recorded in bioarchaeological or forensic anthropological research, their heritability is well documented in the clinical literature (Chen, 2006; Lee and Goose, 1982; Lundström, 1948; Walker, 1951).

There is, however, considerable debate in the clinical and anthropological literature as to the exact cause of dental crowding. Mossey (1999) argues that while the phenotype is ultimately the result of the environment and genes working together, there is evidence to suggest a strong genetic component to various traits of malocclusion. While there is a documented increase in crowding over human evolution, it is generally the result of a disproportion of the dental arches and the size of the teeth (Proffit, 1986), both of which are largely the result of genes. In fact, a study of tooth size of "North American Caucasians" found that individuals with larger teeth also had more evidence of crowding (Doris et al., 1981). Further, work on Amazonian populations by Normando and colleagues (Normando et al., 2013; Normando et al., 2011) has argued for a strong genetic component to crowding and malocclusions; although, differing opinions exist (see McKeever, 2012). Hughes and colleagues (2001) also documented high heritabilities of spacing (crowding and diastemata) among Australian children.

In a clinical setting, the role of external forces such as resting or chewing pressures (Proffit, 1986), and various skeletal, soft tissue, dento-alveolar factors as well as habits (i.e., thumb or finger sucking) (McDonald and Ireland, 1998) have a documented influence on dental development and malocclusion. While many of these factors that lead to crowding (e.g., size of teeth, supernumerary teeth) may be under genetic control, it is difficult to point to one genetic cause for crowding. As such, many studies have highlighted the role of environment in dental crowding and are largely dismissive of a genetic contribution (Harris and Johnson, 1991; Harris and Smith, 1982; King et al., 1993). Proffit (1986), on the other hand, combines both genetics and environment by arguing that slight crowding is likely related to genetic factors, whereas in cases of severe malocclusion, external factors play a larger role.

While the etiology of dental crowding may not be clear, its occurrence may still be important to study in terms of understanding changes in stresses upon the masticatory system, dental reduction, and changes in diet in the evolutionary past of humans. Until now there has not been a way to quantify or define this trait that could be applicable outside of a clinical setting. The system proposed herein to record dental crowding can be systematically recorded in archaeological and medicolegal settings to evaluate questions of anthropological interest.

Finally, these traits of malocclusion (crowding and maxillary and mandibular overjet) may have relevance as traits that are heritable and could have importance in biological distance analyses as well as studies in the estimation of ancestry within forensic anthropology. A recent study on dental morphological variation collected data on dental crowding among modern samples and found that dental crowding could successfully differentiate populations (Maier, 2017). Moreover, there has already been a substantial amount of work exploring population variation in terms of the three types of malocclusion as defined by Angle: Class I normal, Class I malocclusion (anterior crowding), Class II malocclusion (maxillary overjet), and Class III malocclusion (mandibular overjet). Table 1 outlines the various 
TABLE 1. Population variance of malocclusion

\begin{tabular}{llccccc}
\hline \multicolumn{1}{c}{ Study } & \multicolumn{1}{c}{ Ancestry } & $\mathrm{n}$ & $\begin{array}{c}\text { Class I } \\
\text { normal } \%\end{array}$ & $\begin{array}{c}\text { Class I mal- } \\
\text { occlusion \% }\end{array}$ & $\begin{array}{c}\text { Class II mal- } \\
\text { occlusion \% }\end{array}$ & $\begin{array}{c}\text { Class III mal- } \\
\text { occlusion \% }\end{array}$ \\
\hline (Horowitz 1970) & White & 321 & 53.6 & NA & 33.6 & 4.7 \\
& Black & 397 & 76.8 & NA & 11.4 & 6.3 \\
\hline $\begin{array}{l}\text { (Garner and Butt } \\
\text { 1985) }\end{array}$ & Black American & 445 & 27.0 & 44.0 & 16.0 & 8.7 \\
& Kenyan & 505 & 16.8 & 51.7 & 7.9 & 16.8 \\
\hline (Onyeaso 2004)) & Nigerian & 663 & 24.5 & 50.0 & 13.7 & 11.8 \\
\hline (Altemus 1959) & African & 3289 & 16.48 & 66.4 & 12.3 & 4.9 \\
& American & & & & & 12.6 \\
\hline (Lew et al. 1993) & Chinese & 1050 & 58.8 & 52.7 & 21.5 & 3.5 \\
& White & 1000 & 44.3 & 61.1 & 52.2 & 9.1 \\
\hline (Silva and Kang & Latino & 507 & 6.5 & 62.9 & 21.5 & \\
\hline
\end{tabular}

studies that immediately highlight population differences in the various types of malocclusion, thereby illustrating their relevance to anthropological studies of population variation.

\section{Orthodontic Considerations}

Modern orthodontia can impact observations of all of these traits. While braces may seem ubiquitous, they are a relatively new development. In the United States orthodontic work made a marked appearance in the 1950s as the "baby boom" created a larger sample of potential patients. However, the practice did not really take off until the 1970s when the number of qualified orthodontists nearly tripled from the decade before (Asbell, 1990). According to the American Association of Orthodontists (2016), nearly 5,000,000 people were receiving orthodontic care in the United States in 2016, and they estimated that half of the U.S. population could benefit from orthodontic work. In studying traits of malocclusion and the possibility of orthodontic work, it is important to consider various factors that may limit access to treatment. Multiple studies have documented economic and social barriers to receiving orthodontic treatment (Germa et al., 2010; Krey and Hirsch, 2012), as well as ethnic differences in desires for orthodontic treatment (Reichmuth et al., 2005). Additionally, cultural practices and views on beauty can also interfere. For example, in a Nigerian sample of 141 individuals, a study found that 48 (34\%) had artificially created a midline diastema for the "enhancement of personal beauty and aesthetic" (Umanah et al., 2015:226). While orthodontic work could erase many of these traits, there are various factors to consider when studying a set of remains such as socioeconomic or social status, ancestry, and antiquity of the remains (i.e., death prior to 1970 is less likely to have had orthodontic care).

\section{Conclusions}

These traits of malocclusion all figure prominently in clinical discussions of occlusion and are broadly related to conditions that include spacing issues (i.e., diastema and crowding), and deviations from normal occlusion (i.e., maxillary and mandibular overjet). While the midline diastema has been embraced by the ASUDAS and other dental morphologists, the other traits described herein have not. The reason for this finding is likely related to a lack of understanding of the etiology of these conditions; however, it is argued here that these traits show a degree of genetic heritability and could be relevant to studies of population variation. Yet, the environmental component of these traits of occlusion cannot be ignored and may therefore serve as a means to quantify the degree of malocclusion over human evolution. It is hoped that this definition of a scoring system will generate further discussions of traits of malocclusion and that comparative population studies can be generated to further our understanding of population variation and human evolution.

\section{Acknowledgments}

I thank G. Richard Scott for always being supportive and for helping me work through this scoring system. $\mathrm{He}$ is always there to talk teeth with me. 


\section{REFERENCES}

Alt K. W., and Türp J. C. (1998). Hereditary Dental Anomalies. In: Alt KW, Rösing FW, and Teschler -Nicola M, editors. Dental Anthropology: Fundamentals, Limits, and Prospects (pp. 95-128). New York: Springer.

Altemus L. A. (1959). Frequency of the incidence of malocclusion in American Negro children aged twelve to sixteen. The Angle Orthodontist, 29(4), 189-200.

Angle E. H. (1899). Classification of Malocclusion. Dental Cosmos, 41(3), 248-264.

Angle E. H. (1907). Treatment of Malocclusion of the Teeth: Angle's System: White Dental Manufacturing Company.

Asbell M. (1990). A brief history of orthodontics. Am J Orthod Dentofacial Orthop, 98(2), 176-183.

Baume L. J., and Maréchaux S. C. (1974). Uniform methods for the epidemiologic assessment of malocclusion: The development of basic methods by the World Health Organization and the Fédération Dentaire Internationale. Am J Orthod, 66(2), 121-129.

Bezroukov V., Freer T., Helm S., Kalamkarov H., Infirri J. S., and Solow B. (1979). Basic method for recording occlusal traits. Bull WHO, 57(6), 955.

Björk A., Krebs A., and Solow B. (1964). A Method for Epidemiological Registration of Malocculusion. Acta Odontol Scand, 22(1), 27-41.

Burnett S. E., Hawkey D. E., and Turner C. G. (2010). Brief communication: Population variation in human maxillary premolar accessory ridges (MxPAR). Amer J Phys Anthrop, 141(2), 319-324.

Carlson D. S., and Van Gerven D. P. (1977). Masticatory function and post-pleistocene evolution in Nubia. Amer J Phys Anthrop, 46(3), 495-506.

Chen R. Y. P. (2006). Heritability of Occlusal Traits in Primary Dentitions of Brazilian Twins [MS Thesis]: State University o fNew York at Buffalo.

Chu C. H., Zhang C. F., and Jin L. J. (2011). Treating a maxillary midline diastema in adult patients. The Journal of the American Dental Association, 142 (11), 1258-1264.

Corruccini R. S. (1984). An epidemiologic transition in dental occlusion in world populations. Am J Orthod, 86(5), 419-426.

Corruccini R. S., Potter R. H., and Dahlberg A. A. (1983). Changing occlusal variation in Pima Amerinds. Am J Phys Anthropol, 62(3), 317-324.

Dahiya G., Masoud A. I., Viana G., Obrez A., Kusnoto B., and Evans C. A. (2017). Effects of unilateral premolar extraction treatment on the dental arch forms of Class II subdivision malocclusions. Am J Orthod Dentofacial Orthop, 152(2), 232-241.
Dahlberg A. A. (1956). Materials for the Establishment of Standards for Classification of Tooth Characteristics, Attributes, and Techniques in Morphological Studies of the Dentition. Chicago: Zoller Laboratory of Dental Anthropology, University of Chicago.

Doris J. M., Bernard B. W., and Kuftinec M. M. (1981). A biometric study of tooth size and dental crowding. Am J Orthod, 79(3), 326-336.

Edgar H. J. H. (2007). Microevolution of African American dental morphology. Amer J Phys Anthrop, 132(4), 535-544.

Edgar H. J. H. (2017). Dental Morphology: An Illustrated Manual. New York: Routledge.

Garner L. D., and Butt M. H. (1985). Malocclusion in Black Americans and Nyeri Kenyans: an epidemiological study. Angle Orthod, 55, 139-146.

Gass J. R., Valiathan M., Tiwari H. K., Hans M. G., and Elston R. C. (2003). Familial correlations and heritability of maxillary midline diastema. Am J Orthod Dentofacial Orthop, 123(1), 35-39.

Germa A., Kaminski M., and Nabet C. (2010). Impact of social and economic characteristics on orthodontic treatment among children and teenagers in France. Community Dent Oral Epidemiol, 38(2), 171-179.

Gkantidis N., Kolokitha O.-E., and Topouzelis N. (2008). Management of maxillary midline diastema with emphasis on etiology. J Clin Pediatr Dent, 32(4), 265-272.

Grainger R. M. (1967). Orthodontic treatment priority index. Vital Health Stat 2, (25), 1-49.

Hanihara K. (1961). Criteria for classification of crown characters of the human deciduous dentition. J Anthrop Soc Nippon, 69, 27-45.

Harris E. F., and Bailit H. L. (1980). The metaconule: a morphological and familiar analysis of a molar cusp in humans. Amer J Phys Anthrop, 53, 349358.

Harris E. F., and Johnson M. G. (1991). Heritability of craniometric and occlusal variables: A longitudinal sib analysis. Am J Orthod Dentofacial Orthop, 99(3), 258-268.

Harris E. F., and Smith R. J. (1982). Occlusion and Arch Size in Families. The Angle Orthodontist, 52 (2), 135-143.

Hassan R., and Rahimah A. (2007). Occlusion, malocclusion and method of measurements-an overview. Archives of Orofacial Sciences, 2, 3-9.

Horowitz H. S. (1970). A study of occlusal relations in 10 to 12 year old Caucasian and Negro children--summary report. Int Dent J, 20(4), 593-605.

Hrdlička A. (1921). Further studies of tooth morphology. Amer J Phys Anthrop, 4, 141-176. 
Huang W. J., and Creath C. J. (1995). The midline diastema: a review of its etiology and treatment. Pediatr Dent, 17(3), 171-179.

Hughes T., Thomas C., Richards L., and Townsend G. (2001). A study of occlusal variation in the primary dentition of Australian twins and singletons. Arch Oral Biol, 46(9), 857-864.

Irish J. D. (1993). Biological affinities of late Pleistocene through modern Africal aboriginal populations: the dental evidence [Ph.D.]. Tempe, AZ.: Arizona State University.

Irish J. D., and Morris D. H. (1996). Canine mesial ridge (Bushman canine) dental trait definition. Amer J Phys Anthrop, 99, 357-359.

Kamath M., and Arun A. (2016). Midline diastema. International Journal of Orthodontic Rehabilitation, 7 (3), 101-104.

Keene H. J. (1963). Distribution of diastemas in the dentition of man. Amer J Phys Anthrop, 21(4), $437-$ 441.

King L., Harris E. F., and Tolley E. A. (1993). Heritability of cephalometric and occlusal variables as assessed from siblings with overt malocclusions. Am J Orthod Dentofacial Orthop, 104(2), 121-131.

Krey K.-F., and Hirsch C. (2012). Frequency of orthodontic treatment in German children and adolescents: influence of age, gender, and socioeconomic status. Eur J Orthod, 34(2), 152-157.

Larsen C. S. (2015). Bioarchaeology: Interpreting behavior from the human skeleton. Cambridge: Cambridge University Press.

Lasker G. W. (1950). Genetic analysis of racial traits of the teeth. Cold Spring Harbor Symp Quant Biol: Cold Spring Harbor Laboratory Press. p 191 $-203$.

Lavelle C. L. B. (1970). The distribution of diastemas in different human population samples. Eur J Oral Sci, 78(1-4), 530-534.

Lee G., and Goose D. (1982). Heritability of dental occlusal variables in a family study in Liverpool, UK. Arch Oral Biol, 27(11), 987-989.

Lew K. K., Foong W. C., and Loh E. (1993). Malocclussion prevalence in an ethnic Chinese population. Aust Dent J, 38, 442-449.

Little R. M. (1975). Irregularity index: A quantitative score of mandibular anterior alignment. Am J Orthod Dentofacial Orthop, 68(5), 554-563.

Lundström A. (1948). Tooth Size and Occlusion in Twins. Basel: Karger Publishers.

Maier C. (2017). The Combination of Cranial Morphoscopic and Dental Morphological Methods to Improve the Forensic Estimation of Ancestry [PhD dissertation]: University of Nevada, Reno.

McDonald F., and Ireland A. J. (1998). Diagnosis of the Orthodontic Patient. Oxford: Oxford University Press.
McKeever A. (2012). Genetics versus environment in the aetiology of maloccclusion. Br Dent J, 212(11), 527-528.

McVay T. J., and Latta G. H. (1984). Incidence of the maxillary midline diastema in adults. The Journal of Prosthetic Dentistry, 52(6), 809-811.

Mongtagu A. (1989). Growing Young. Granby, Massachusetts: Bergin \&Garvey Publishers, Inc.

Morris D. H. (1970). On deflecting wrinkles and the Drypoithecus pattern in human mandibular molars. Amer J Phys Anthrop, 32, 97-104.

Morris D. H., Hughes S. G., and Dahlberg A. A. (1978). Uto-Aztecan premolar: the anthropology of a dental trait. In: Bulter PM, and Joysey KA, editors. Development, Function and Evolution of Teeth (pp. 69-79). London: Academic Press.

Mossey P. A. (1999). The Heritability of Malocclusion: Part 2. The Influence of Genetics in Malocclusion. Br J Orthod, 26(3), 195-203.

Nainar S. H., and Gnanasundaram N. (1989). Incidence and etiology of midline diastema in a population in south India (Madras). The Angle Orthodontist, 59(4), 277-282.

Normando D., Almeida M. A. O., and Quintão C. C. A. (2013). Dental crowding. The Angle Orthodontist, 83(1), 10-15.

Normando D., Faber J., Guerreiro J. F., and Quintão C. C. A. (2011). Dental occlusion in a split Amazon indigenous population: genetics prevails over environment. PLoS One, 6(12), e28387.

Onyeaso C. O. (2004). Prevalence of malocclusion among adolescents in Ibadan, Nigeria. Am J Orthod Dentofacial Orthop, 126(5), 604-607.

Orthodontists A. A. o. (2016). Legislative Priorities. http://wwwglaoorg/Portals/0/\%212016\% 20Congressional\% 20Leave-Behind $\% 20 \% 281 \% 29 p d f$.

Pilloud M. A., Maier C., and Scott G. R. (2017). Molar crenulation trait definition and population variation. American Academy of Forensic Sciences. New Orleans, LA.

Proffit W. R. (1986). On the aetiology of malocclusion. Br J Orthod, 13(1), 1-11.

Reichmuth M., Greene K. A., Orsini M. G., Cisneros G. J., King G. J., and Kiyak H. A. (2005). Occlusal perceptions of children seeking orthodontic treatment: Impact of ethnicity and socioeconomic status. Am J Orthod Dentofacial Orthop, 128(5), 575 -582 .

Richardson E. R., Malhotra S. K., Henry M., Little R. G., and Coleman H. T. (1973). Biracial study of the maxillary midline diastema. The Angle Orthodontist, 43(4), 438-443.

Schultz A. H. (1948). The relation in size between premaxilla, diastema and canine. Amer J Phys Anthrop, 6(2), 163-180.

Sciulli P. W. (1998). Evolution of the dentition in prehistoric Ohio valley Native Americans: II. mor- 
phology of the deciduous dentition. Amer J Phys Anthrop, 106, 189-205.

Scott G. R. (1977). Classification, sex dimorphism, association, and population variation of the canine distal accessory ridge. Hum Biol, 49 (3), 453-469.

Scott G. R. (1980). Population variation of Carabelli's trait. Hum Biol, 52, 63-78.

Scott G. R., and Irish J. D. (2017). Human Crown and Root Morphology: The Arizona State University Dental Anthropology System. Cambridge: Cambridge University Press.

Shashua D., and Årtun J. (1999). Relapse after orthodontic correction of maxillary median diastema: a follow-up evaluation of consecutive cases. The Angle Orthodontist, 69(3), 257-263.

Silva R. G., and Kang D. S. (2001). Prevalence of malocclusion among Latino adolescents. Am J Orthod Dentofacial Orthop, 119, 313-315.

Singhal P., Namdev R., Jindal A., Bodh M., and Dutta S. (2015). A Multifaceted approach through two by four appliances for various Malocclusions in mixed dentition. Clinical Dentistry (09743979), 9(4).

Tabbaa S., Guigova I., and Preston C. (2010). Midline diastema caused by tongue piercing. J Clin Orthod, 44(7), 426-428.

Tang E. L. K., and Wei S. H. Y. (1993). Recording and measuring malocclusion: A review of the literature. Am J Orthod Dentofacial Orthop, 103(4), 344351.

Tomes C. S. (1914). A manual of dental anatomy: human and comparative. Philadelphia: P. Blakiston's Son.

Turner C. G. (1970). New classification of nonmetrical dental variation: Cusps 6 and 7. American Association for Physical Anthropologists. Washington, D.C.

Turner C. G. (1971). Three-rooted mandibular first permanent molars and the question of American Indian origins. Amer J Phys Anthrop, 34, 299-242.

Turner C. G., Nichol C. R., and Scott G. R. (1991). Scoring procedures for key morphological traits of the permanent dentition: the Arizona State University dental anthropology system. In: Kelley MA, and Larsen CS, editors. Advances in Dental Anthropology (pp. 13-31). New York: WileyLiss.

Türp J., Greene C., and Strub J. (2008). Dental occlusion: a critical reflection on past, present and future concepts. J Oral Rehabil, 35(6), 446-453.

Umanah A., Omogbai A.-A., and Osagbemiro B. (2015). Prevalence of artificially created maxillary midline diastema and its complications in a selected Nigerian population. Afr Health Sci, 15 (1), 226-232.
Van Kirk L. E., and Pennell E. H. (1959). Assessment of malocclusion in population groups. Am J Orthod, 45(10), 752-758.

Walker N. F. (1951). Tooth size and occlusion in twins. Amer J Hum Genet, 3(1), 77-77. 